\title{
Vertical Craniofacial Morphology and its Relation to Temporomandibular Disorders
}

\author{
Paula Furlan Bavia ${ }^{1}$, Renata Cunha Matheus Rodrigues Garcia ${ }^{1}$ \\ ${ }^{1}$ Department of Prosthodontics and Periodontology, Piracicaba Dental School, University of Campinas, Piracicaba, Brazil.
}

\section{Corresponding Author:}

Renata Cunha Matheus Rodrigues Garcia

Av. Limeira, 13414-903, Piracicaba

Brazil

Phone: + 5519 2106-5240

Fax: + 5519 2106-5211

E-mail: regarcia@fop.unicamp.br

\section{ABSTRACT}

Objectives: This study investigated the association between craniofacial morphology and temporomandibular disorders in adults. The influence of different craniofacial morphologies on painful temporomandibular disorders was also evaluated. Material and Methods: A total of 200 subjects were selected, including 100 with temporomandibular disorders (TMD) and 100 without TMD (control), diagnosed by research diagnostic criteria for temporomandibular disorders. All subjects were submitted to lateral cephalometric radiographs, and classified as brachyfacial, mesofacial, or dolichofacial by Ricketts' analysis. Data were analysed by Tukey-Kramer and Chi-square tests.

Results: No association between craniofacial morphology and TMD was found $(\mathrm{P}=0.6622)$. However, brachyfacial morphology influences the presence of painful TMD $(\mathrm{P}=0.0077)$.

Conclusions: Craniofacial morphology is not related to temporomandibular disorders in general.

Keywords: facial asymmetry; facial bones; orofacial pain; temporomandibular joint disorders.

\author{
Accepted for publication: 27 June 2016 \\ To cite this article: \\ Bavia PF, Rodrigues Garcia RC. \\ Vertical Craniofacial Morphology and its Relation to Temporomandibular Disorders \\ J Oral Maxillofac Res 2016;7(2):e6 \\ URL: http://www.ejomr.org/JOMR/archives/2016/2/e6/v7n2e6.pdf \\ doi: $10.5037 /$ jomr.2016.7206
}




\section{INTRODUCTION}

Temporomandibular disorders (TMD) are among the most common causes of orofacial pain of nondental origin and are characterized by pain in the temporomandibular joint and/or masticatory muscles, conditions that could be aggravated by chewing and other mandibular activities, such as excessive mandibular opening due to wide yawning, laughing and/or biting on large objects $[1,2]$. Signs and symptoms of TMD occur frequently in the general population and its treatment involves a multidisciplinary team including several health professionals other than dentists [ $\underline{3}]$.

TMD may arise from etiological factors, such as macro- and micro-traumas, adverse life events, stress, arthritic and arthrotic changes by systemic conditions, repetitive trauma associated with ageing and tooth loss [3]. Parafunctional habits and emotional/psychological aspects can also influence the development and/or maintenance of TMD signs and symptoms [4-9]. Furthermore, craniofacial morphology has also been considered another factor related to TMD [10].

Yang et al. [11], suggested that the skeletal characteristics of patients with disc displacement are influenced by the sagittal relationship established according to mandible size. In addition, some authors also reported association of disc displacement with/ without reduction with linear and angular posterior measurements. Individuals with disc displacement usually have short ramus, height mandibular body length and a backward rotation of the mandible ramus [11-14]. TMJ disc displacement was also positively associated with mandibular asymmetry [12-13]. On the other hand, craniofacial features, such as angulation of the Frankfurt/occlusal plane and inter-pupillary axis, were not related to TMD [15]. Yang et al. [11] and Kwan et al. [14] used the magnetic resonance imaging (MRI) to diagnose TMD-disc displacement. Although MRI is currently accepted as the gold standard for TMD evaluation [16], clinical TMD examination is of decisive importance for the diagnosis of TMD and especially for the evaluation of the temporomandibular joint [17]. In this sense, research diagnostic criteria for temporomandibular disorders (RDC/TMD) was developed to cover the most common TMD and it has been widely used in TMD research [18]. Besides the different methods used to assess TMD $[\underline{11}, 14,15]$, there are no studies focusing on the relationship between vertical craniofacial morphology (i.e., brachyfacial, mesofacial, and dolichofacial patterns) and TMD, highlighting the importance of the subject. Thus, the aim of this study was to investigate the association of vertical craniofacial morphology with temporomandibular disorders in adults diagnosed by the research diagnostic criteria for temporomandibular disorders.

\section{MATERIAL AND METHODS Subjects}

This cross-sectional study was carried out from $1^{\text {st }}$ of August, 2013 to $6^{\text {th }}$ of June, 2015 and included 200 subjects ranging from 18 to 50 years of age. Subjects were assigned to two groups $(n=100)$. The first group was diagnosed with painful or non-painful TMD (experimental) and the second had no TMD (control). A sample size test based on a previous study [19] indicated that 100 volunteers in each group would be enough to detect significant differences with a test power of $80 \%$ and an error probability of $5 \%$. The subjects were recruited from Piracicaba Dental School, University of Campinas (UNICAMP) and included patients, students and staff. To be included in the experimental group, subjects were required to meet the following inclusion criteria: age 18 to 50 years; TMD diagnosed by RDC/TMD; complete natural dentition (except for missing third molars) and good general and oral health.

The control had to meet the same criteria, excluding TMD diagnosis. Subjects were excluded if they presented with malocclusions such as anterior open bite, unilateral or bilateral posterior crossbite; parafunctional habits (bruxism or tooth grinding); facial deformities (severe facial asymmetry, cleft palate, cleft lip, masseteric hypertrophy); previous maxillofacial surgery; neurological or psychological disorders; pregnancy; removable partial or complete dentures; and/or intraoral appliances. Of the 296 subjects initially examined, 96 were excluded for the following reasons: having missing teeth $(n=49)$; malocclusions $(n=9)$, parafunctional habits $(n=20)$; orthodontic treatment $(\mathrm{n}=2)$; maxillofacial surgery $(\mathrm{n}=1)$; pregnancy $(\mathrm{n}=1)$; and missing radiography $(\mathrm{n}=14)$. All subjects had an RDC/TMD examination and were then assigned to an experimental group and control.

All participants have read and signed a written informed consent form. This study was approved by the Ethics Committee of Piracicaba Dental School, University of Campinas (research protocol \#022/2012), and recorded in the Brazilian Registry of Clinical Trials database (No. RBR-87rdwv).

After selection, all participants underwent conventional lateral cephalogram followed by 
cephalometric analysis to determine their craniofacial morphology. Participants were also measured and weighed on a mechanical scale (MIC 1/C A, Micheletti, São Paulo, Brazil) while standing with their feet together and with the Frankfurt plane parallel to the floor. Body mass index (BMI) was calculated considering the ratio between weight and height $\left(\mathrm{kg} / \mathrm{m}^{2}\right)[20]$.

\section{TMD diagnosis}

All subjects were submitted to clinical examinations to diagnose TMD using axis I of the RDC/TMD. They were evaluated by a single trained researcher who had been previously calibrated. Calibration was made by two examiners (one of whom was an RDC/ TMD expert) applying the RDC/TMD to 12 subjects with TMD signs and symptoms and 8 healthy ones. The Kappa index was 0.96 (95\% confidence interval = 0.89 to 1$)$.

Clinical criteria for diagnosis among patients in the experimental group were as follows: RDC Group I, presenting with myofascial pain and with or without limited opening; RDC Group II, presenting disc displacement with or without reduction and with or without limiting opening; and RDC Group III, presenting arthralgia or arthritis or osteoarthrosis. Those presenting none of the characteristics described in the RDC groups were considered to have no TMD and were thus assigned to the control.

\section{Craniofacial morphology}

Conventional lateral cephalogram radiographs were obtained for all subjects to identify their craniofacial morphology. Wearing a lead apron, subjects were positioned in the cephalostat with the sagittal plane perpendicular to the X-ray path, the Frankfurt plane parallel to the floor, their teeth in the maximum intercuspal position, and their lips slightly pressed together [21]. The cephalogram radiographs were taken according to a standardized protocol using the same cephalometric unit (Kodak 8000C, Eastman Kodak Company, Rochester, USA). The cephalometric analyses were performed by a single investigator, who was blinded to the RDC/TMD diagnoses. Images were interpreted using Radiocef Studio 2.0 software (Radiomemory, Belo Horizonte, Brazil). Craniofacial morphology was determined by the vertical growth coefficient (VERT) index, which is the arithmetic mean of the difference between five cephalometric measures (facial axis, anterior lower facial height, mandibular plane, mandibular arch, and facial depth) divided by the standard deviation [22]. The craniofacial morphology of each subject was classified as: dolichofacial (below -0.5), mesofacial (between -0.49 and +0.49 ), and brachyfacial (above $+0.5)$ (Figure 1).

\section{Statistical analysis}

Data were analysed by Tukey-Kramer and Likelihood Ratio Chi-Square tests. All statistical results were considered significant when $\mathrm{P}$ values were $<0.05$. Parametric data were expressed as mean and SD (M [SD]). All statistical analyses were performed using the SAS software (Release 9.3. SAS Institute Inc., Cary, USA).

\section{RESULTS}

Data concerning age, gender and BMI of the TMD individuals (with and without pain) and control subjects without TMD are shown in Table 1. A homogeneous distribution was observed between groups $(\mathrm{P}>0.05)$. There were significant differences for age $(\mathrm{P}=0.027)$, as the subjects with TMD presented a mean of 27.8 (6.1) years old, and the control subjects showed a mean of 25.9 (5.2) years old. BMI values were also different between groups $(\mathrm{P}=0.043)$, with the TMD subjects showing an index of $23.7 \mathrm{KgF}$ (3.6) and those without TMD an index of $22.71(2.7)$

Data distribution regarding the axis I evaluations (RDC/TMD) are shown in Table 2. Muscle disorders were observed in 87 subjects. Concerning articular disorders, 37 patients were diagnosed with RDC Group II (disc displacements) and 62 with RDC Group III (arthralgia/arthritis/arthrosis).

Figure 2 shows the frequency of single and multiple RDC/TMD diagnoses. With regard to the single diagnoses, Group I muscle disorders were observed in $25 \%$ of the patients, Group II disc displacements in $8 \%$, and Group III in 3\%. Multiple group diagnoses involved $64 \%$ of the patients.

Table 1. Anthropometric characteristics of subjects

\begin{tabular}{l|c|c|c}
\hline & $\begin{array}{c}\text { With TMD } \\
\text { (painful and } \\
\text { non-painful) }\end{array}$ & $\begin{array}{c}\text { Without } \\
\text { TMD }\end{array}$ & P \\
\hline Female & 90 & 90 & - \\
\hline Male & 10 & 10 & - \\
\hline Mean age $^{\text {a }}$ (SD), years & $27.8(6.1)$ & $25.9(5.2)$ & $0.027^{\mathrm{a}}$ \\
\hline Mean BMI $^{\mathrm{b}}$ (SD), KgF & $23.7(3.6)$ & $22.71(2.7)$ & $0.043^{\mathrm{b}}$ \\
\hline
\end{tabular}

aStatistically significant at the level $\mathrm{P}<0.05$ (Tukey-Kramer test). ${ }^{b}$ No statistically significant at the level $\mathrm{P}<0.05$ (Tukey-Kramer test). $\mathrm{TMD}=$ temporomandibular disorders; $\mathrm{BMI}=$ body mass index; $\mathrm{SD}=$ standard deviation; $\mathrm{KgF}=$ kilogram-force . 


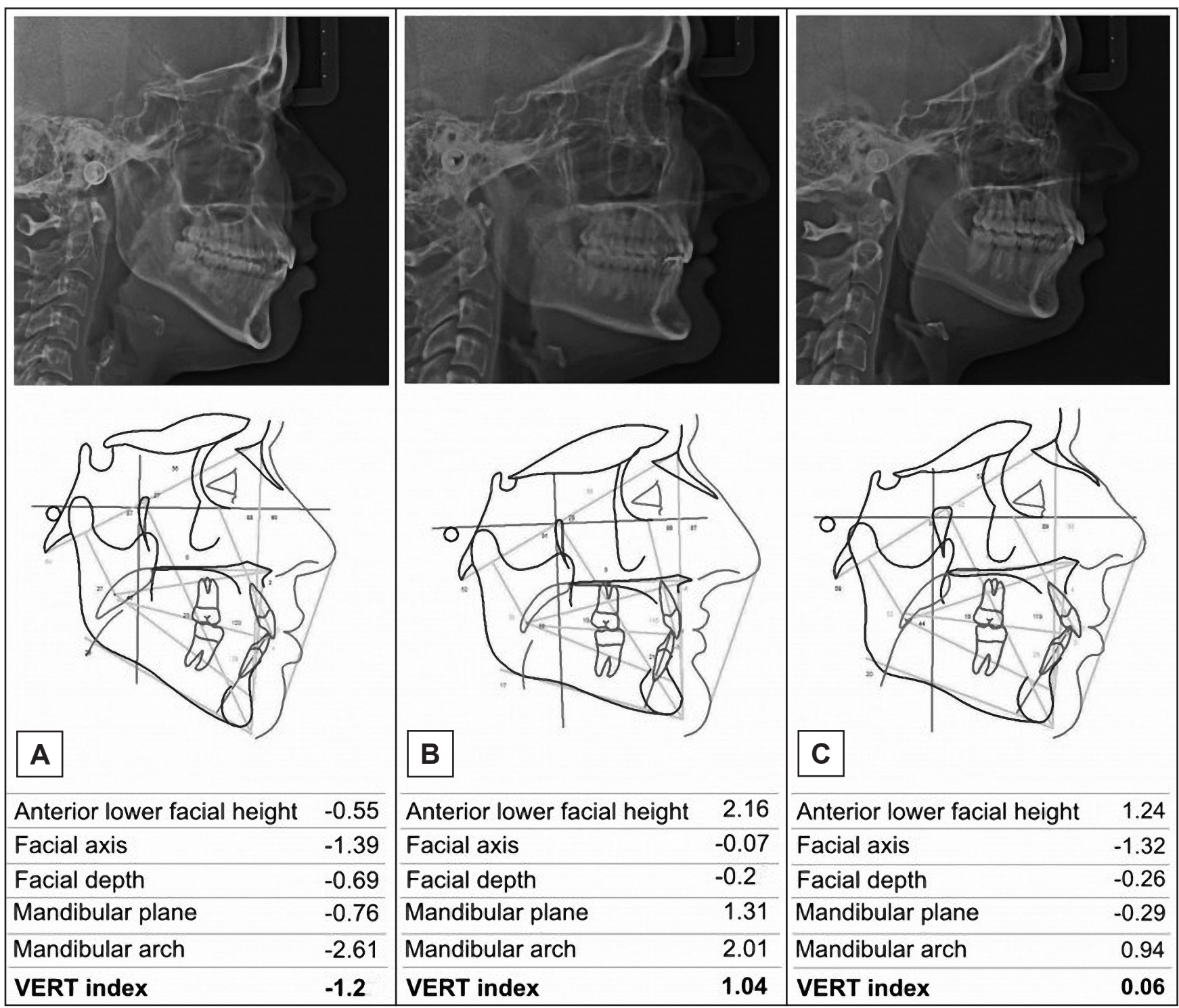

Figure 1. Craniofacial morphology classification. $\mathrm{A}=$ dolichofacial (VERT index below -0.5 ); $\mathrm{B}=$ brachyfacial (VERT index above +0.5 ); $\mathrm{C}=$ mesofacial (VERT index between -0.49 and +0.49 ).

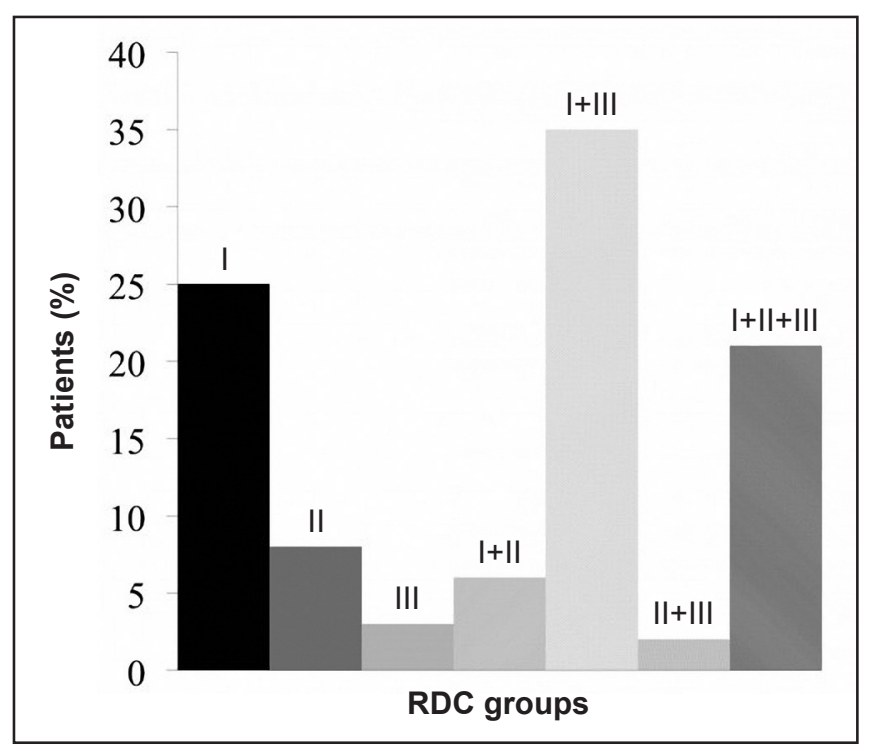

Figure 2. Distribution of single and multiple research diagnostic criteria (RDC) axis I diagnoses.
Table 2. Distribution of RDC/TMD axis I diagnosis

\begin{tabular}{l|c}
\hline \multicolumn{1}{c|}{ RDC group } & $\begin{array}{c}\text { Number of } \\
\text { subjects }\end{array}$ \\
\hline Muscle disorders & 71 \\
\hline Myofascial pain & 16 \\
\hline Myofascial pain with limited opening & 36 \\
\hline Disc displacements & 0 \\
\hline Disc displacement with reduction & 1 \\
\hline $\begin{array}{l}\text { Disc displacement without reduction, with limited } \\
\text { opening }\end{array}$ & 61 \\
\hline $\begin{array}{l}\text { Disc displacement without reduction, without limited } \\
\text { opening }\end{array}$ & 1 \\
\hline Arthralgia, arthritis, arthrosis & 0 \\
\hline Arthralgia & \\
\hline Osteoarthritis of the temporomandibular joint & \\
\hline Osteoarthrosis of the temporomandibular joint &
\end{tabular}

$\mathrm{RDC} / \mathrm{TMD}=$ research diagnostic criteria for temporomandibular disorders; $\mathrm{RDC}=$ research diagnostic criteria . 
The number and frequency of subjects with different craniofacial patterns for control (without TMD) and experimental (with TMD) groups are in Table 3. A difference $(\mathrm{P}=0.0207)$ in the frequency distribution was observed between brachy- and dolicho-facial subjects in the control group (without TMD), with brachyfacial subjects being in greater proportion $(\mathrm{n}=46,53.49 \%)$. No such difference $(\mathrm{P}=0.1738)$ was found in the experimental group (with TMD). Furthermore, no association between craniofacial morphology and TMD were found $(\mathrm{P}=0.6622)$.

In relation to the entire TMD group, pain was observed in 92 individuals (Table 4). Differences were found among the brachyfacial $(n=40)$, dolichofacial $(\mathrm{n}=23)$, and mesofacial $(\mathrm{n}=29)$ craniofacial patterns in subjects with painful TMD $(\mathrm{P}=0.0077)$. TMD subjects without pain had no differences towards craniofacial morphology.

\section{DISCUSSION}

This study demonstrated the TMD is not associated with vertical craniofacial morphology. Regarding demographic data, differences between groups were observed for age and BMI. The age of participants ranged from 18 to 50 years old, and the BMI values of both groups fell into the normal weight category [21].
Considering that obesity is associated with obstructive sleep apnea [23] , and the latter with the occurrence of TMD [24], we suggest that these differences did not interfere with the results, because our subjects were in normal weight. Concerning the RDC axis I diagnoses, only 36 of the TMD subjects had a single TMD diagnosis, while the remaining 64 had multiple diagnoses. This finding is similar to those reported in previous studies, showing that a combination of muscular and articular disorders frequently occurs clinically [25-26]. As TMD subjects usually have multiple diagnoses, the present study focused on TMD to assign the subjects to the experimental group, independent of their specific RDC diagnoses [25].

Although the experimental group had a higher frequency of brachyfacial patients, no significant difference in the frequency of craniofacial morphologies was observed. In contrast, subjects in the control showed no differences between brachyfacial and dolichofacial morphologies. Although there was a higher proportion of brachyfacial subjects without TMD, no association was found between craniofacial morphology and TMD (independent of pain). This finding is in disagreement with those previously reported [10-11]; such disharmony might be due to the different cephalometric variables evaluated in those previous studies,

Table 3. Comparison of the frequency distribution and the association between different craniofacial morphologies and TMD

\begin{tabular}{c|c|c|c|c}
\hline \multirow{2}{*}{ Groups } & \multicolumn{3}{|c|}{ Craniofacial morphology } & \multirow{2}{*}{ P } \\
\cline { 2 - 4 } & $\begin{array}{c}\text { Brachyfacial } \\
(\%)\end{array}$ & $\begin{array}{c}\text { Dolichofacial } \\
(\%)\end{array}$ & $\begin{array}{c}\text { Mesofacial } \\
(\%)\end{array}$ & \\
\hline $\begin{array}{c}\text { Without TMD } \\
(\mathbf{n}=\mathbf{1 0 0})\end{array}$ & $46(53.49)$ & $24(48.98)$ & $30(46.15)$ & $0.0207^{\mathrm{a}}$ \\
\hline $\begin{array}{c}\text { With TMD } \\
(\mathbf{n}=\mathbf{1 0 0})\end{array}$ & $40(46.51)$ & $25(51.02)$ & $35(53.85)$ & $0.1738^{\mathrm{b}}$ \\
\hline
\end{tabular}

a Statistically significant at the level $\mathrm{P}<0.05$ (Tukey-Kramer test).

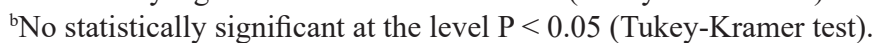

Likelihood ratio Chi-Square was used to estimate the association between craniofacial morphology and TMD.

It was verified no association at the level of $\mathrm{P}<0.05(\mathrm{P}=0.6622)$.

$\mathrm{TMD}=$ temporomandibular disorders; $\mathrm{n}=$ total number of subjects without or with TMD.

Table 4. Association between craniofacial morphology and TMD with and without pain

\begin{tabular}{l|c|c}
\hline \multirow{2}{*}{$\begin{array}{c}\text { Craniofacial } \\
\text { morphology }\end{array}$} & \multicolumn{2}{|c}{$\begin{array}{c}\text { TMD group } \\
(\mathbf{n}=\mathbf{1 0 0})\end{array}$} \\
\cline { 2 - 3 } & $\begin{array}{c}\text { With pain } \\
(\mathbf{\% )}\end{array}$ & $\begin{array}{c}\text { Without pain } \\
\mathbf{( \% )}\end{array}$ \\
\hline Brachyfacial & $40(100)$ & $0(0)$ \\
\hline Dolichofacial & $23(92)$ & $2(8)$ \\
\hline Mesofacial & $29(82.86)$ & $6(17.14)$ \\
\hline \multicolumn{1}{c}{ P value } & $0.0077^{\mathrm{a}}$ & $>0.05^{\mathrm{b}}$ \\
\hline
\end{tabular}

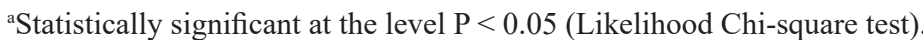

${ }^{b}$ No statistically significant at the level of $\mathrm{P}<0.05$ (Likelihood Chi-square test).

$\mathrm{TMD}=$ temporomandibular disorders; $\mathrm{n}=$ total number of subjects per TMD group . 
assessing cephalometric variables individually and not determining the vertical craniofacial morphologies in their subjects. Most of the studies that found associations between cephalometric variables and TMD evaluated TMD characteristics anamnestically and clinically by palpation/auscultation or by radiographic/magnetic resonance imaging $[11,14-$ 15]. Our study, however, used the RDC/TMD axis I diagnostic protocol, which is the most frequently used, validated, and accepted instrument for clinical research [18].

Our data also showed that all brachyfacial subjects in the experimental group presented painful TMD. These data can probably be explained by differences in the fibre-type composition of their masticatory muscles [27-28]. There is a higher proportion of type II fibres in the masseter of short-faced brachyfacial subjects; these fibres are characterized by rapid contraction and lower resistance to fatigue [29-30]. Thus, as type II fibres are less resistant to fatigue, which is often associated with the onset of muscle pain, it might explain the presence of pain in all brachyfacial subjects with TMD [31].

Considering that a high percentage of subjects presented more than one RDC/TMD diagnosis, it was impossible to evaluate the association between craniofacial morphology and the specific RDC diagnoses. This could be a limitation of this study and thus further studies are needed to investigate these specific associations.

Another relevant consideration involves the lateral cephalogram used in this study to classify the subjects as brachyfacial, mesofacial and dolichofacial. The lateral cephalogram is used to analyse the vertical or anteroposterior relationship of the maxilla and mandible to the cranial base, while the posteroanterior cephalogram can indicate facial asymmetry by comparing the left and the right sides of the face [32-33]. Some authors have used a posteroanterior cephalogram to verify changes in some cephalometric variables in subjects with TMD [32,34]. However, in the present study, the Ricketts' method of VERT, widely used to define craniofacial patterns, and the lateral cephalogram were used because the subjects' vertical facial height was considered for the craniofacial classification. Besides, according to Claro et al. [35], the VERT index minimizes possible distortions arising from regional morphological variations, which may occur when defining facial patterns based on individual cephalometric measurements. The VERT index presents some shortcomings related to the adjustment between average values, allowing a true correspondence between factors [35].

\section{CONCLUSIONS}

Within the constraints of the present study, the results contribute to clinical practice. There is no association between craniofacial morphology and general temporomandibular disorders.

\section{ACKNOWLEDGMENTS AND DISCLOSURE STATEMENTS}

The authors report no conflict of interest related to this study.

\section{REFERENCES}

1. McNeill C, editor. In: Temporomandibular disorders: guidelines for classification, assessment, and management. 2nd ed. Chicago: Quintessence Books;1993. p.11-8.

2. Suvinen TI, Reade PC, Kemppainen P, Könönen M, Dworkin SF. Review of aetiological concepts of temporomandibular pain disorders: towards a biopsychosocial model for integration of physical disorder factors with psychological and psychosocial illness impact factors. Eur J Pain. 2005 Dec;9(6):613-33. [Medline: 15978854] [doi: 10.1016/j.ejpain.2005.01.012]

3. Armijo-Olivo S, Magee D. Cervical musculoskeletal impairments and temporomandibular disorders. J Oral Maxillofac Res. 2012 Oct-Dez;3(4):e4. [Medline: 24422022] [PMC free article: 3886095] [doi: 10.5037/jomr.2012.3404]

4. Blanco Aguilera A, Gonzalez Lopes L, Blanco Aguilera E, De la Hoz Aizpura JL, Rodriguez Torronteras A, Segura Saint-Gerons R, Blanco Hungría A. Relationship between self-reported sleep bruxism and pain in patients with temporomandibular disorders. J Oral Rehabil. 2014 Aug;41(8): 564-72. [Medline: 24750430] [doi: 10.1111/joor.12172]

5. Fernandes G, van Selms MK, Gonçalves DA, Lobbezoo F, Camparis CM. Factors associated with temporomandibular disorders pain in adolescents. J Oral Rehabil. 2015 Feb;42(2):113-9. [Medline: 25244610] [doi: 10.1111/joor.12238]

6. Häggman-Henrikson B, Rezvani M, List T. Prevalence of whiplash trauma in TMD patients: a systematic review. J Oral Rehabil. 2014 Jan;41(1):59-68. [Medline: 24443899] [doi: 10.1111/joor.12123]

7. Manfredini D, Winocur E, Ahlberg J, Guarda-Nardini L, Lobbezoo F. Psychosocial impairment in temporomandibular disorders patients. RDC/TMD axis II findings from a multicenter study. J Dent. 2010 Oct;38(10): 765-72. [Medline: 20600559] [doi: 10.1016/j.jdent.2010.06.007] 
8. Reissman DR, John MT, Seedorf H, Doering S, Schierz O. Temporomandibular disorder pain is related to the general disposition to be anxious. J Oral Facial Pain Headache. 2014 Fall;28(4):322-30. [Medline: 25347167]

9. Gremillion HA. The relationship between occlusion and TMD: an evidence-based discussion. J Evid Based Dent Pract. 2006 Mar;6(1):43-7. [Medline: 17138396] [doi: 10.1016/j.jebdp.2005.12.014]

10. Bertram S, Moriggi A, Neunteufel A, Rudisch A, Emshoff R. Lateral cephalometric analysis of mandibular morphology: discrimination among subjects with and without temporomandibular joint disk displacement and osteoarthrosis. J Oral Rehabil. 2012 Feb;39(2):93-9. [Medline: 21923719] [doi: 10.1111/j.1365-2842.2011.02251.x]

11. Yang IH, Moon BS, Lee SP, Ahn SJ. Skeletal differences in patients with temporomandibular joint disc displacement according to sagittal jaw relationship. J Oral Maxillofac Surg. 2012 May;70(5):e349-60. [Medline: 22169732] [doi: 10.1016/j.joms.2011.08.027]

12. Sakar O, Calişiri F, Marşan G, Oztas E. Evaluation of the effects of temporomandibular joint disc displacement and its progression on dentocraniofacial morphology in symptomatic patients using posteroanterior cephalometric analysis. Cranio. 2013 Jan;31(1):23-31. [Medline: 23461259] [doi: 10.1179/crn.2013.004]

13. Almăşan OC, Băciuţ M, Hedeşiu M, Bran S, Almăşan H, Băciuţ G. Posteroanterior cephalometric changes in subjects with temporomandibular joint disorders. Dentomaxillofac Radiol. 2013;42(1):20120039. [Medline: 23253565] [PMC free article: 3729188] [doi: 10.1259/dmfr.20120039]

14. Kwon HB, Kim H, Jung WS, Kim TW, Ahn SJ. Gender differences in dentofacial characteristics of adult patients with temporomandibular disc displacement. J Oral Maxillofac Surg. 2013 Jul;71(7):1178-86. [Medline: 23455416] [doi: 10.1016/j.joms.2012.12.015]

15. Ciancaglini R, Colombo-Bolla G, Gherlone EF, Radaelli G. Orientation of craniofacial planes and temporomandibular disorder in young adults with normal occlusion. J Oral Rehabil. 2003 Sep;30(9):878-86. [Medline: 12950968] [doi: $10.1046 / \mathrm{j} .1365-2842.2003 .01070 . x$ ]

16. Vogl TJ, Lauer HC, Lehnert T, Naguib NNN, OttlP, Filmann N, Soekamto H, Nour-Eldin NEA. The value of MRI in patients with temporomandibular joint dysfunction: Correlation of MRI and clinical findings. Eur J Radiol. 2016 Apr;85(4):714-9. [Medline: 26971413] [doi: 10.1016/i.ejrad.2016.02.001]

17. Witulski S, Vogl TJ, Rehart S, Ottl P. Evaluation of the TMJ by means of clinical TMD examination and MRI diagnostics in patients with rheumatoid arthritis. Biomed Res Int. 2014;2014:328560. [Medline: 25243130] [PMC free article: 4160621] [doi: $\underline{10.1155 / 2014 / 328560]}$

18. Dworkin SF, LeResche L. Research diagnostic criteria for temporomandibular disorders: review, criteria, examinations and specifications, critique. J Craniomandib Disord. 1992 Fall;6(4):301-55. [Medline: 1298767]

19. Sonnesen L, Bakke M, Solow B. Temporomandibular disorders in relation to craniofacial dimensions, head posture and bite force in children selected for orthodontic treatment. Eur J Orthod. 2001 Apr; 23(2):179-92. [Medline: 11398555] [doi: 10.1093/ejo/23.2.179]

20. Obesity: preventing and managing the global epidemic. Report of a WHO consultation. World Health Organ Tech Rep Ser. 2000;894:i-xii, 1-253. [Medline: 11234459 ]

21. Bósio JA, Burch JG, Tallents RH, Wade DB, Beck FM. Lateral cephalometric analysis of asymptomatic volunteers and symptomatic patients with and without bilateral temporomandibular joint disk displacement. Am J Orthod Dentofacial Orthop. 1998 Sep;114(3):248-55. [Medline: 9743129] [doi: 10.1016/S0889-5406(98)70206-9]

22. Ricketts RM. Perspective in the clinical application of cephalometrics. The first fifty years. Angle Orthod. 1981 Apr; 51(2):115-50. [Medline: 6942666 ]

23. LaGrotte C, Fernandez-Mendoza J, Calhoun SL, Liao D, Bixler EO, Vgontzas AN. The relative association of obstructive sllep apnea, obesity and excessive daytime sleepness with incident depression: a longitudinal, population-based study. Int J Obes (Lond). 2016 May 24. [Medline: 27143032] [doi: 10.1038/ijo.2016.87]

24. Sanders AE, Essik GK, Fillingim R, Knott C, Ohrbach R, Greenspan JD, Diatchenko L, Maixner W, Dubner R, Bair E, Miller VE, Slade GD. Sleep apnea symptoms and risk of temporomandibular disorder: OPPERA cohort. J Dent Res. 2013 Jul;92(7 Suppl):70S-7S. [Medline: 23690360] [PMC free article: 3706181] [doi: 10.1177/0022034513488140]

25. Manfredini D, Piccotti F, Ferronato G, Guarda-Nardini L. Age peaks of different RDC/TMD diagnoses in a patient population. J Dent. 2010 May;38(5):392-9. [Medline: 20100537] [doi: 10.1016/j.jdent.2010.01.006]

26. Wieckiewicz M, Grychowska N, Wojciechowski K, Pelc A, Augustyniak M, Sleboda A, Zietek M. Prevalence and correlation between TMD based on RDC/TMD diagnoses, oral parafunctions and psychoemotional stress in Polish university students. Biomed Res Int. 2014;2014:472346. [Medline: 25121100] [PMC free article: 4119893] [doi: $10.1155 / 2014 / 472346]$

27. Tuxen A, Bakke M, Pinholt EM. Comparative data from young men and women on masseter muscle fibres, function and facial morphology. Arch Oral Biol. 1999 Jul;44(6):509-18. [Medline: 10401529] [doi: 10.1016/S0003-9969(99)00008-4]

28. Rowlerson A, Raoul G, Daniel Y, Close J, Maurage CA, Ferri J, Sciote JJ. Fiber-type differences in masseter muscle associated with different facial morphologies. Am J Orthod Dentofacial Orthop. 2005 Jan;127(1):37-46. [Medline: 15643413] [PMC free article: 3848722] [doi: 10.1016/j.ajodo.2004.03.025]

29. Farella M, Bakke M, Michelotti A, Rapuano A, Martina R. Masseter thickness, endurance and exercise-induced pain in subjects with different vertical craniofacial morphology. Eur J Oral Sci. 2003 Jun;111(3):183-8. [Medline: 12786947] [doi: 10.1034/j.1600-0722.2003.00035.x] 
30. Korfage JA, Koolstra JH, Langenbach GE, van Eijden TM. Fiber-type composition of the human jaw muscles-(part 2) role of hybrid fibers and factors responsible for inter-individual variation. J Dent Res. 2005 Sep;84(9):784-93. [Medline: 16109985]

31. Maton B, Rendell J, Gentil M, Gay T. Masticatory muscle fatigue: endurance times and spectral changes in the electromyogram during the production of sustained bite forces. Arch Oral Biol. 1992;37(7):521-9. [Medline: 1444896] [doi: 10.1016/0003-9969(92)90134-T]

32. Almăşan OC, Băciuţ M, Hedeşiu M, Bran S, Almăşan H, Băciuţ G. Posteroanterior cephalometric changes in subjects with temporomandibular joint disorders. Dentomaxillofac Radiol. 2013;42(1):20120039. [Medline: 23253565] [PMC free article: 3729188 ] [doi: 10.1259/dmfr.20120039]

33. Ahn SJ, Lee SP, Nahm DS. Relationship between temporomandibular joint internal derangement and facial asymmetry in women. Am J Orthod Dentofacial Orthop. 2005 Nov;128(5):583-91. [Medline: 16286205] [doi: 10.1016/j.ajodo.2004.06.038]

34. Sakar O, Calişir F, Marşan G, Oztaş E. Evaluation of the effects of temporomandibular joint disc displacement and its progression on dentocraniofacial morphology in symptomatic patients using posteroanterior cephalometric analysis. Cranio. 2013 Jan;31(1):23-31. [Medline: 23461259] [doi: 10.1179/crn.2013.004]

35. Claro CA, Abrão J, Reis SA. Association between overbite and craniofacial growth pattern. Braz Oral Res. 2010 OctDec;24(4):425-32. [Medline: 21180963] [doi: 10.1590/S1806-83242010000400009]

\section{To cite this article:}

Bavia PF, Rodrigues Garcia RC.

Vertical Craniofacial Morphology and its Relation to Temporomandibular Disorders

J Oral Maxillofac Res 2016;7(2):e6

URL: http://www.ejomr.org/JOMR/archives/2016/2/e6/v7n2e6.pdf

doi: $10.5037 /$ jomr.2016.7206

Copyright (C) Bavia PF, Rodrigues Garcia RC. Published in the JOURNAL OF ORAL \& MAXILLOFACIAL RESEARCH (http://www.ejomr.org), 30 June 2016.

This is an open-access article, first published in the JOURNAL OF ORAL \& MAXILLOFACIAL RESEARCH, distributed under the terms of the Creative Commons Attribution-Noncommercial-No Derivative Works 3.0 Unported License, which permits unrestricted non-commercial use, distribution, and reproduction in any medium, provided the original work and is properly cited. The copyright, license information and link to the original publication on (http://www.ejomr.org) must be included. 